\title{
AGENTE MIRIM DE DEFESA CIVIL: EDUCAÇÃO AMBIENTAL PARA PREVENÇÃO E REDUÇÃO DE RISCOS DE DESASTRES NATURAIS EM BLUMENAU, SANTA CATARINA
}

JUNIOR CIVIL DEFENSE AGENT: ENVIRONMENTAL EDUCATION FOR NATURAL DISASTER PREVENTION AND RISK REDUCTION IN BLUMENAU, SANTA CATARINA AGENTE JUVENIL DE DEFENSA CIVIL: EDUCACIÓN AMBIENTAL PARA PREVENCIÓN Y REDUCCIÓN DE RIESGOS DE DESASTRES NATURALES EN BLUMENAU, SANTA CATARINA

Rafaela Vieira ${ }^{1}$ Jefferson Ribeiro ${ }^{2}$

${ }^{1}$ Doutora em Geografia pela UFSC. Docente do Programa de Pós-Graduação em Engenharia Ambiental da Fundação Universidade Regional de Blumenau (FURB), Blumenau, SC, Brasil.

2Mestre em Engenharia Ambiental pela Fundação Universidade Regional de Blumenau (FURB), Blumenau, SC, Brasil.

Resumo: Em Blumenau, localizada na bacia hidrográfica do rio Itajaí, em Santa Catarina, a Defesa Civil vem desenvolvendo em escolas municipais, estaduais e privadas, atividades para sensibilização da população frente aos riscos de desastres naturais. Dentre as ações, existe a capacitação dos estudantes para conhecer o que é risco e como proceder antes, durante e após um desastre. O projeto intitulado de Agente Mirim de Defesa Civil (AMDC) busca mediar conhecimentos para a prevenção e a Redução de Riscos de Desastres (RRD) ao longo de um ano. Este estudo procura descrever o projeto AMDC com base em seus procedimentos metodológicos, por meio do acompanhamento dos encontros e da aplicação de formulários comparativos. Os resultados obtidos durante os acompanhamentos demonstram que os encontros propostos pela Defesa Civil de Blumenau capacitam os estudantes com embasamentos nas práticas da Educação Ambiental (EA). Palavras-chave: Educação ambiental; Procedimentos metodológicos; Risco de desastre.

Abstract: In Blumenau, located in the Itajaí river basin, in the Brazilian state of Santa Catarina, Civil Defense has been developing in municipal, state and private schools, through activities to raise public awareness of the risks of natural disaster. These actions include training pupils to understand what risk is, and what they should do before, during and after a disaster. The project, entitled "Agente Mirim de Defesa Civil (AMDC) [Junior Civil Defense 
Agent] seeks to mediate knowledge for Disaster Risk Reduction (DRR) and prevention over the course of a year. This study describes the AMDC project, based on methodological procedures through meetings and the application of comparative questionnaires. The results obtained during meetings organized by the Blumenau Civil Defense enhanced the students' education, giving them a knowledge of the basics of Environmental Education (EE). Keywords: Environmental education, methodological procedures, disaster risk.

Resumen: En Blumenau, ubicada en la cuenca hidrográfica del río Itajaí, en Santa Catarina, la Defensa Civil ha estado desarrollando en las escuelas municipales, estatales y privadas, actividades para sensibilizar a la población frente al riesgo de desastres naturales. Entre las acciones preventivas, existe la capacitación de los estudiantes para conocer qué es riesgo y cómo proceder antes, durante y después de un desastre. El proyecto titulado Agente Juvenil de Defensa Civil (AJDC) busca mediar conocimiento para la prevención y Reducción del Riesgo de Desastres (RRD) a más de un año. Este estudio tiene como objetivo describir el proyecto AJDC basado en sus procedimientos metodológicos, mediante la supervisión de las reuniones y la aplicación de formas comparativas. Los resultados obtenidos durante los acompañamientos demuestran que las reuniones propuestas por la Defensa Civil de Blumenau, capacitan a los estudiantes con base en las prácticas de Educación Ambiental (EA).

Palabras clave: Educación ambiental, Procedimientos Metodológicos, Riesgos de Desastres.

\section{INTRODUÇÃO}

A ocorrência dos desastres naturais tem proporcionado constantes impactos negativos nas esferas ambientais, sociais e econômicas dos países. O Brasil é o único país da América Latina presente na lista das 10 primeiras nações com mais pessoas afetadas por desastres naturais (CRED/UNISDR, 2015). Isto implica grandes desafios de gestão para os estados brasileiros. De acordo com Bessa Junior, Doustdar e Cortesi (2011), nos desastres naturais ocorridos no país, em especial na região serrana do Rio de Janeiro e na região litorânea do Paraná, foi possível observar uma debilidade não apenas física e ambiental do sistema, mas também de caráter social.

Estas características também foram evidenciadas no Estado de Santa Catarina. De acordo com Ribeiro et al. (2014), durante o final de 2008, aconteceram o predomínio de chuvas de elevada intensidade, propiciando deslizamentos de terra, enxurradas, inundações e processos erosivos nas regiões da Grande Florianópolis, Litoral Norte e, especialmente, na bacia hidrográfica do Rio Itajaí. Segundo Xavier, Barcellos e Freitas (2014), a precipitação acumulada no início do mês de novembro de 2008 ultrapassou a média histórica, agravando-se pela incidência de chuvas intensas ocorridas entre os dias 22 e 24, promovendo efeitos devastadores a vários municípios.

Segundo Brito Junior et al. (2014), o incremento do número de desastres tem demonstrado a vulnerabilidade das sociedades, sendo imprescindível esforços suplementares das organizações 
humanitárias em fornecer auxílio as pessoas. De acordo com Narváez, Lavell e Ortega (2009), a gestão de riscos abrange formas variadas para minimizar e evitar os impactos causados por desastres, indo desde a elaboração e implementação de políticas e estratégias para formulação de ações e instrumentos específicos de redução e controle. Os autores também confirmam que tentar corrigir condições de insegurança, de forma isolada e sem o processo da promoção de medidas de prevenção e políticas de desenvolvimento, torna-se uma estratégia de baixo impacto e quase sempre ineficaz em longo prazo.

Seguindo esta linha de pensamento, o programa Cidades Resilientes, elaborado pela Organização das Nações Unidas (ONU), determina dez passos que buscam tornar as cidades mais resilientes aos desastres, dentre as ações à destaque para atividades de prevenção como os programas de educação e treinamento, impulsionando que os conhecimentos de redução de riscos de desastres estejam presentes nas escolas e nas comunidades (UNISDR, 2012). No Brasil, destaca-se a Política Nacional de Proteção e Defesa Civil (PNPDEC), Lei n. 12.608/2012 que alterou a Lei de Diretrizes e Bases da Educação Nacional (LDB), Lei n. 9.394/96, instituindo que a grade curricular do Ensino Fundamental e Médio contenham os princípios da proteção e defesa civil e a educação ambiental de forma integrada aos conteúdos.

Pautando-se nas políticas públicas internacionais e nacionais, a Defesa Civil (DC) de Blumenau, município localizado na bacia hidrográfica do Rio Itajaí, em Santa Catarina, vem desenvolvendo dois projetos de Educação Ambiental (EA) para prevenção e Redução de Riscos de Desastres (RRD) nas escolas municipais, estaduais e privadas presentes no município. $O$ projeto "Defesa Civil na escola" (DCE) capacita todos os anos alunos do $4^{\circ}$ ano do Ensino Fundamental de 10 escolas e o projeto "Agente Mirim de Defesa Civil" (AMDC) constitui-se em uma ação complementar que abrange uma das 10 escolas que participaram do DCE no ano subsequente.

O intuito do projeto AMDC é capacitar estudantes durante um ano letivo, por meio de técnicas que auxiliem a conhecer o que é risco e como proceder antes, durante e após um desastre. O projeto contribui para o empoderamento social, valorizando e instigando os estudantes a envolver-se nas atividades de prevenção aos riscos de desastres promovidos pela Defesa Civil (DEFESA CIVIL/BLUMENAU, 2014). O objetivo desta pesquisa é descrever o projeto AMDC com base em seus procedimentos metodológicos e estratégias de ensino e aprendizagem, vinculados à EA conforme utilizados pela DC de Blumenau. Com os resultados obtidos pela observação dos encontros e pela aplicação de formulários, busca-se contribuir para a consolidação do projeto, identificando-se possíveis recomendações de modificações nas metodologias empregadas.

\section{Metodologia}

O método de procedimento utilizado foi o estudo de caso, por ser uma investigação empírica que focaliza acontecimentos contemporâneos dentro de um contexto (YIN, 2005). Busca-se descrever como é o projeto $\mathrm{AMDC}$, para prevenção e mitigação aos riscos de desastres em Blumenau. As técnicas utilizadas foram: pesquisa documental, bibliográfica e de campo com 
observação direta intensiva de ações que envolveram estudantes e técnicos da DC do Município de Blumenau, localizado no Estado de Santa Catarina. O projeto de pesquisa passou pelo Comitê de Ética da Fundação Universidade Regional de Blumenau (FURB), sendo aprovado para sua aplicação durante o ano de 2016.

O universo de pesquisa foram os 30 estudantes do $6^{\circ}$ ano do Ensino Fundamental dos períodos matutino e vespertino da Escola de Educação Básica Hermam Hamann e dois mediadores do projeto AMDC (Figura 1). Estes mediadores são assistentes sociais, responsáveis por possibilitar e organizar todas as etapas do projeto na escola e demais localidades visitadas pelos estudantes. O recorte temporal da pesquisa foi o ano de 2016. A unidade escolar localiza-se no bairro Nova Esperança, compreendendo uma área vulnerável a deslizamentos. Ao longo do ano escolar os alunos participam de atividades teóricas e práticas sobre os riscos de desastres naturais em diversas localidades de Blumenau. Durante os encontros, diferentes metodologias, estratégias e instrumentos foram utilizados pelos mediadores.

Figura 1 - Escola sede dos Agentes Mirins ano de 2016

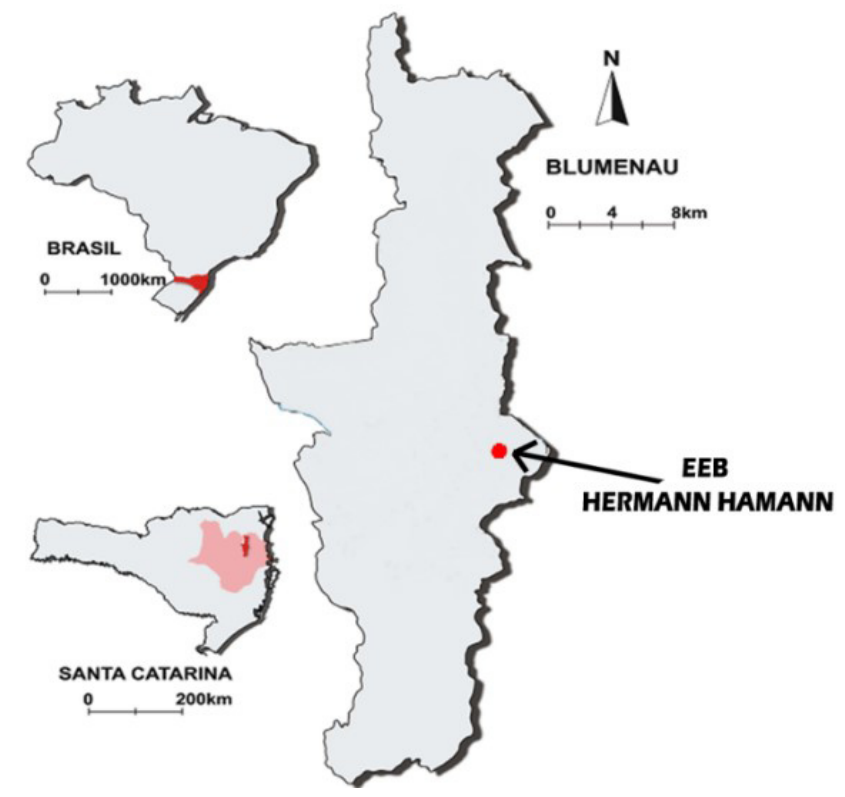

Fonte: Tachini et al. (2009), adaptada pelos autores.

Participam dos encontros diversos representantes de instituições vinculadas ao município, especialmente nas saídas a campo, entre eles: (1) Polícia Militar, (2) Vereadores Mirins, (3) Instituto Cíntia Lopes, (4) Fundação do Meio Ambiente de Blumenau (FAEMA), (5) Sociedade Cooperativa de Trabalho Médico (Unimed), (6) Secretaria Municipal da Educação (SEMED), (7) UBRO Radioamadores de Blumenau, (9) Empresa Odebrecht Ambiental, (10) Bombeiros, (11) Diretoria de Geologia da Secretaria de Defesa ao Cidadão (SEDECI), (12) Museu da Água de Blumenau, (13) Exército, (14) Escola de Educação Básica Hermann Hamann e (15) representante da Universidade Regional de Blumenau (FURB). 
Para descrevero projeto AMDC e suas práticas pedagógicas, foram realizadosacompanhamentos de todas as 27 intervenções realizadas na Escola de Educação Básica Hermam Hamann e demais localidades do município. Dentre as 27 intervenções, 16 foram encontros que se caracterizaram como aulas, para os quais foram utilizados formulário de descrição e análise, preenchidos pelo próprio pesquisador, visando à descrição das atividades realizadas pelas duas assistentes sociais da Defesa Civil e de 11 parceiros da prefeitura.

Além de analisar dados como duração do encontro, práticas abordadas e interação dos alunos com a aula, o formulário visou identificar a aplicação dos conteúdos conceituais, procedimentais e atitudinais. De acordo com os Parâmetros Curriculares Nacionais (PCN) de 1998, deve-se aprofundar estes conteúdos uma vez que, nesta fase de maturidade, os alunos já percebem e compreendem relações mais complexas do espaço geográfico. Ou seja, são capazes de realizar sistematizações, podendo compreender aspectos metodológicos da área quando estudam as relações entre cultura, sociedade, estado, território, entre outros fatores (BRASIL, 1998). Ao término das atividades previstas no projeto, os dados dos formulários foram comparados, verificando os principais pontos abordados nas aulas e contrastando se houve evolução obtida com as ações, analisando-se os procedimentos metodológicos, estratégias de ensino e aprendizagem, instrumentos e critérios de avaliação vinculados à EA.

\section{Resultados E disCUSSÕES}

Durante o ano de 2016, o projeto AMDC foi composto por 27 intervenções realizadas pela Defesa Civil, sendo seis pré-encontros para seleção dos estudantes participantes, preparação e posse, 16 encontros efetivos, para os quais foram aplicados os formulários de descrição e análise e cinco encontros adicionais (Figura 2).

\section{Pré-encontros}

Inicialmente, a DC de Blumenau realiza a escolha da escola que participará do projeto AMDC, dentre aquelas que, no ano anterior, participaram do projeto DCE. Após esta escolha, são fixados folders nos murais da instituição, informando os preparativos para realização das inscrições pelos alunos interessados. Dois dias após este primeiro contato, os técnicos da DC retornam à escola e entregam as fichas para a inscrição. A seleção realizada em 2016 envolveu um número maior de inscrições do que as 30 vagas disponíveis. Por este motivo, foi necessário realizar uma entrevista para selecionar os participantes do projeto, efetuada pelas próprias mediadoras da DC. Por fim, ocorreu a divulgação dos nomes dos estudantes selecionados, por meio de folders espalhados pela escola.

Seguindo o cronograma do projeto, foi agendado com os futuros agentes mirins um encontro preparatório para explicar sobre a cerimônia de posse da vaga, realizada após uma semana, junto à escola. Durante o evento da posse os estudantes recebem seu colete repassado pelos 
AMDC do ano anterior, assim como a carteirinha de identificação, entregue pela mesa de honra, constituída por várias autoridades municipais, dentre elas o prefeito de Blumenau. Devidamente empossados, os agentes iniciam os encontros previstos pela DC, os quais ocorreram de forma quinzenal e que foram descritos durante este artigo.

Figura 2 - Fluxograma das intervenções realizadas em 2016 no projeto AMDC

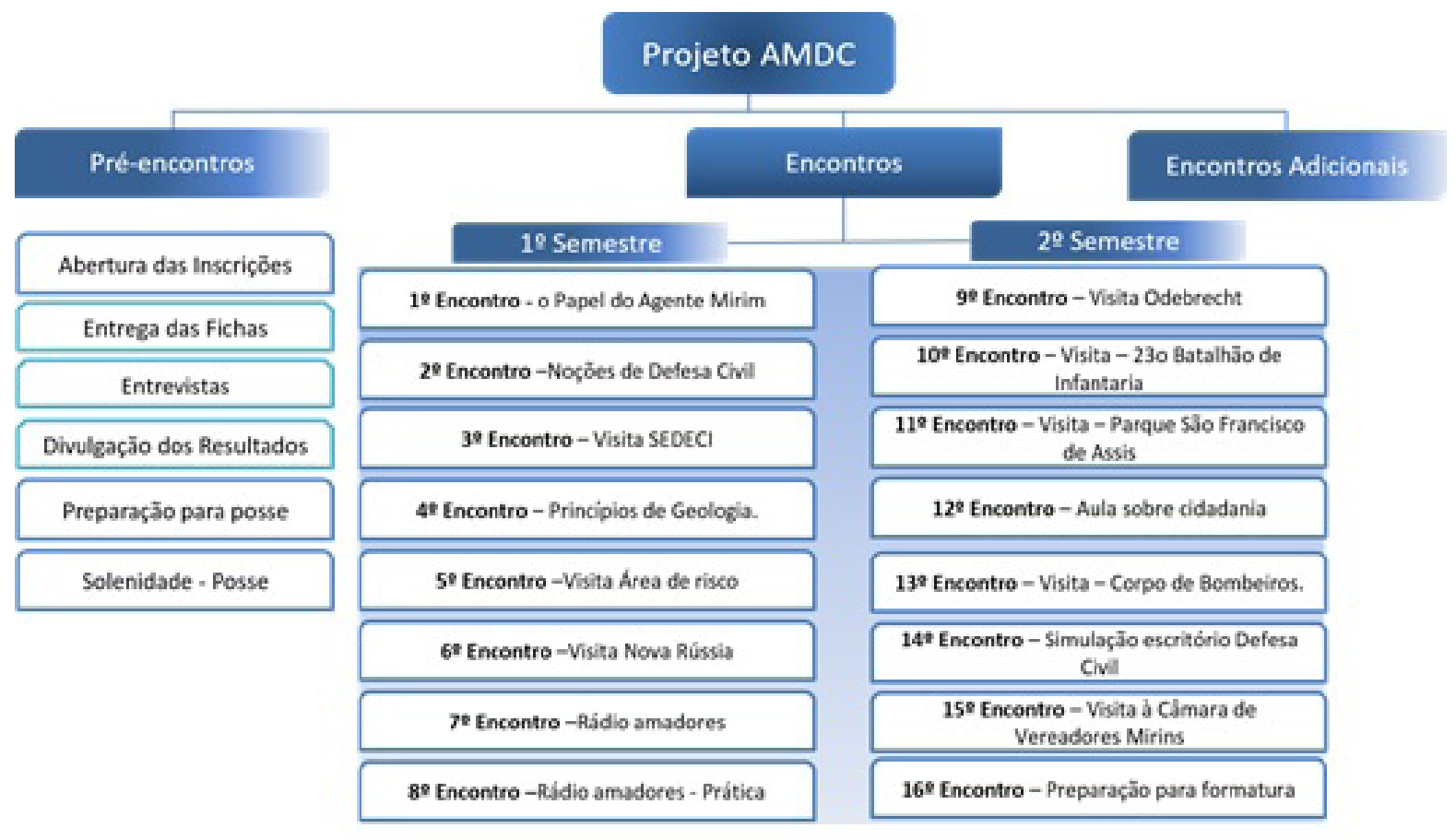

Fonte: Autoria própria

\section{ENCONTROS}

Os 16 encontros realizados durante o projeto foram diversificados e contaram com a participação de várias entidades, dentre elas órgãos públicos e privados. As atividades tiveram durações diferenciadas, obtendo como média o tempo de 86 minutos por encontro. Em alguns casos, devido às atividades de campo, o período superou 130 minutos. De acordo com os dados obtidos nos formulários de descrição e análise, o comportamento da turma foi calmo ou empolgado na maioria das vezes. Em quatro encontros os estudantes encontravam-se agitados com a própria temática proposta para o encontro, tendo-se que interferir e solicitar com que os agentes mirins respeitassem o momento em que o mediador explicava os conteúdos e os conceitos (Figura 3).

A metodologia mais frequentemente utilizada no projeto articula a teoria com a prática, presente em sete encontros (Figura 3). No decorrer das atividades, foi possível observar o interesse dos estudantes pelas ações, em especial pelas atividades práticas. Contudo, nem 
todos os encontros proporcionaram a interação do coletivo de estudantes. Em determinadas ocasiões, a participação ficou dividida. Em alguns momentos a turma inteira participou, em outros houve destaque para pequenos grupos de alunos (Figura 3). Observou-se que, na maioria dos encontros realizados fora da unidade escolar, houve maior interação do coletivo de estudantes.

Com base nos três pilares da educação, foram analisadas as relações dos conteúdos conceituais, procedimentais e atitudinais. De acordo com Zabala (1998), conceitos são termos abstratos e fazem referência ao conjunto de objetos, fatos ou símbolos que possuem características comuns. Os conteúdos procedimentais incluem técnicas, regras, métodos, destrezas, estratégias e procedimentos, ou seja, um conjunto de ações destinadas a atingir um objetivo. Diferente disto, os atitudinais englobam uma gama de outros conteúdos, podendo ser agrupados em valores, atitudes e normas. Pode-se afirmar que praticamente todos os encontros do AMDC abrangeram estes três pilares da educação, com exceção de três que não apresentaram conteúdos procedimentais. Em todos os demais os alunos tiveram contato com conceitos básicos da temática e com as questões atitudinais que deveriam estar presentes durante as atividades didáticas.

Figura 3 - Demonstrativo das características dos encontros

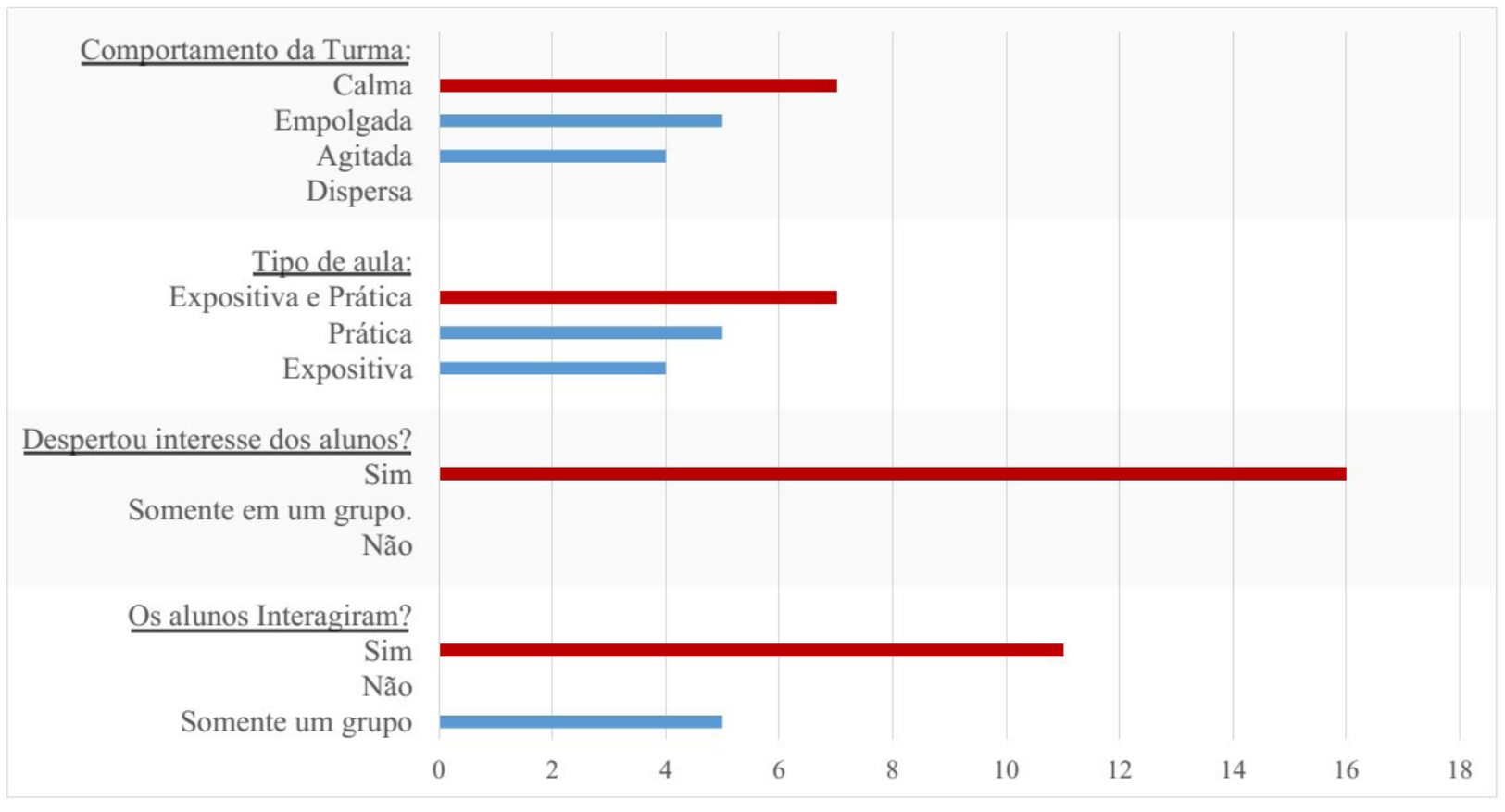

Fonte: Autoria própria.

\section{Detalhamentos dos encontros:}

\section{1 - O papel do agente mirim}

No primeiro encontro foi realizada uma aula explicativa sobre o papel do Agente Mirim. Inicialmente fez-se uma breve introdução dos projetos DCE e AMDC que compõem o programa Defesa Civil na Escola. De acordo com Ribeiro et al. (2016), este programa é tido como referência 
na prevenção para desastres naturais no Estado de Santa Catarina, colaborando com medidas preventivas e mitigadoras ao sensibilizar e capacitar os alunos das escolas municipais. Nesta aula não houve atividades práticas, o contexto do encontro relacionou-se à importância do agente mirim junto ao bairro Nova Esperança. Estiveram presentes conteúdos conceituais, como as breves explicações das atividades desenvolvidas pela DC, sendo os simulados, as vistorias e o plano de contingência. A descrição das atividades que seriam desenvolvidas dentro do Projeto AMDC, exemplificando o cronograma do projeto, assim como explicações das competências dos estudantes e esclarecimentos sobre suas atribuições.

Os conteúdos procedimentais foram: ler oralmente em conjunto com a turma, interpretar e resumir ideias. Os atitudinais estiveram relacionados à possibilidade de promover roda de debate entre os estudantes, respeitando o momento de cada um. A intenção é que os alunos sejam multiplicadores, divulgando informações à família e outros grupos sociais sobre o papel de todos na manutenção da saúde e procurando conhecer/aceitar a opinião de outras pessoas, exercitando a valorização de diferentes ideias.

\section{2 - Noções de defesa civil}

No segundo encontro, as duas assistentes sociais da DC explicaram aos alunos o que é a Defesa Civil e suas funções. Durante a aula foi realizada uma atividade prática com a mascote da DC, a cachorra Mayla, que apresentou sua capacidade de localizar objetos aos estudantes. A situação contexto da aula estava atrelada em conhecer as atribuições da DC, órgão que os agentes mirins estavam inseridos. Entre os conteúdos conceituais destacam-se as competências da DC e suas ações de prevenção, mitigação, preparação, resposta e recuperação. É abordado também o detalhamento da origem do órgão e das competências da Secretaria de Defesa do Cidadão (SEDECI), exemplificando cada diretoria dentro da secretaria.

Entre os conteúdos procedimentais, esteve presente a formulação de hipóteses sobre questõesproblema. Nos momentos finais do encontro, foi solicitado aos estudantes a formação de grupos para elaborar perguntas a serem realizadas no encontro seguinte, durante a visita para conhecer as dependências da SEDECI. As assistentes sociais também proporcionaram aos estudantes a leitura em conjunto das perguntas elaboradas. Neste encontro os conteúdos atitudinais estiveram atrelados às questões como respeitar a opinião do próximo e as diferenças, individuais e grupais, desenvolvendo atitudes de solidariedade e valorização e promoveram o empenho dos alunos nas atividades individuais e de grupo.

\section{3 - Visita à SEDECI}

A situação contexto da aula esteve relacionada a conhecer a SEDECI e as diretorias de Defesa Civil, Políticas Integradas de Segurança, Projetos e Geologia, Análise de Riscos Naturais. Os estudantes tiveram a oportunidade de aprender sobre as competências desenvolvidas pela secretaria e suas diretorias (Figura 4). Algumas atividades práticas foram oportunizadas aos estudantes durante o encontro, havendo destaque para a Diretoria de Geologia, Análise de Riscos Naturais. Os agentes mirins conheceram alguns tipos de rochas, presentes em Blumenau e aprenderam sobre os instrumentos utilizados em campo. Entre os conteúdos conceituais, 
houve destaque para o processo de monitoramento da régua do rio, assim como explicações básicas sobre a prefeitura, definindo como funcionam as diretorias da SEDECI. Por meio desta integração foi possível conhecer as diferentes formações geológicas do município e as ações para gestão de risco de desastres.

Figura 4 - Agentes Mirins na Defesa Civil de Blumenau

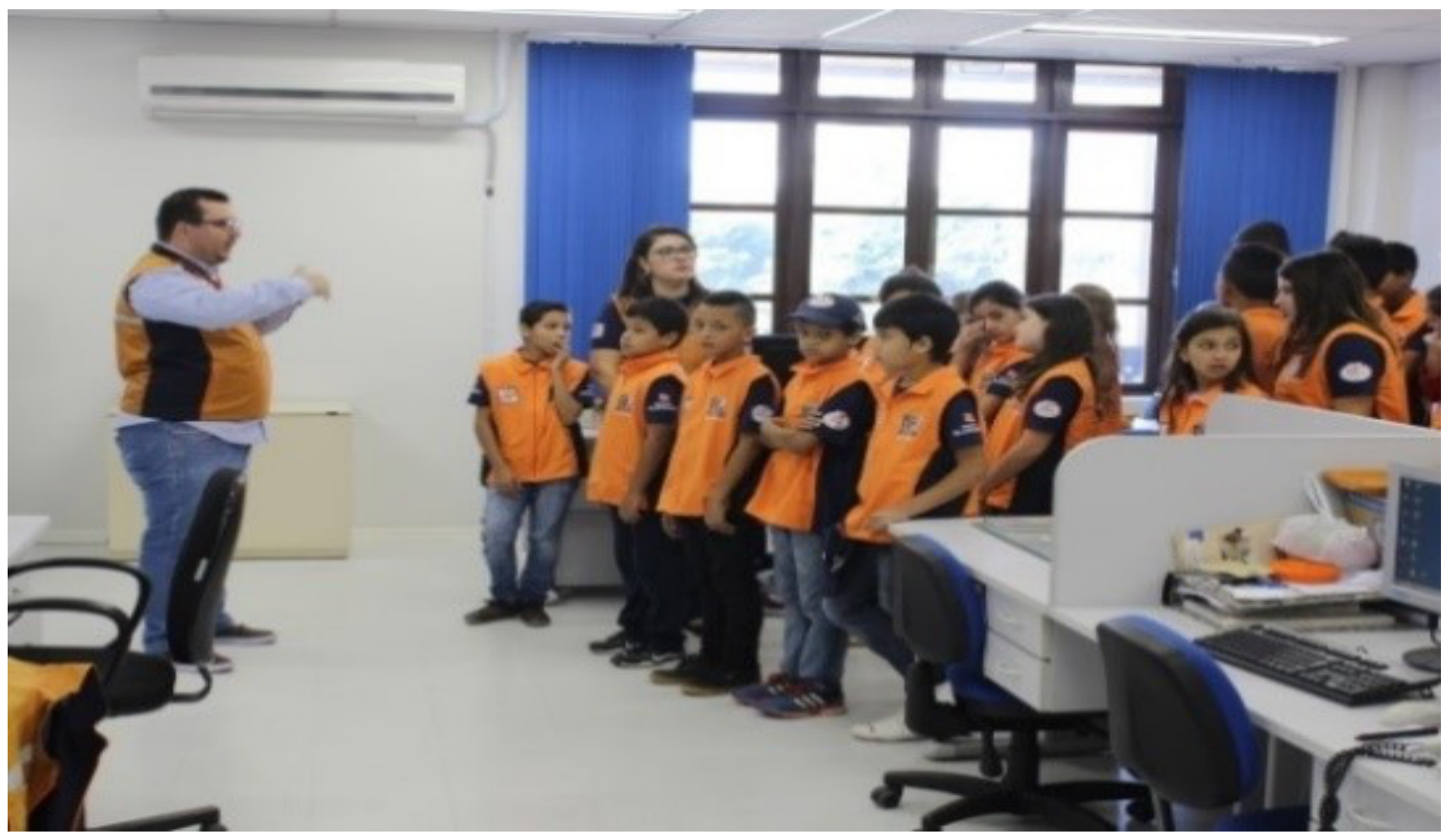

Fonte: Autoria própria.

Neste encontro não houve conteúdos procedimentais. Nos conteúdos atitudinais, foi proporcionado o momento para debate das perguntas desenvolvidas pelos alunos no encontro anterior. Diante desta condição, os estudantes respeitaram o momento de expressão dos outros. As assistentes sociais da Defesa Civil enfatizaram aos alunos a questão de respeitar o conhecimento repassado pelos diferentes mediadores.

\section{4 - Princípios de geologia}

Neste encontro a temática estava relacionada com a área da geologia e da geografia. A atividade foi expositiva com grande aporte em recursos visuais, tais como vídeos do desastre de 2008, tragédia que assolou Santa Catarina e sobre construções em áreas de risco. A situação contexto do encontro foi pautada na geologia do bairro Nova Esperança, averiguando as suas possíveis áreas de risco. As explicações foram promovidas pelo geógrafo do setor de geologia da prefeitura.

Os conteúdos conceituais abordados foram os desastres naturais, apresentando-se os eventos mais recorrentes no Brasil. Conceituou-se também vulnerabilidade e risco, enfatizando os deslizamentos e foram exploradas as noções básicas de geologia e geografia. Diferenciou-se evento natural e desastre natural, apresentando-se os principais fatores que potencializam os 
desastres, como a inclinação da encosta, ausência da vegetação, entre outros. Nos conteúdos procedimentais, observou-se a promoção do debate sobre as fotos presentes nos slides do geógrafo, descrevendo se a situação encontra-se em risco ou não. A presença dos conteúdos atitudinais estava relacionada a respeitar o momento de expressão dos outros colegas e respeitar o conhecimento repassado pelo mediador.

De acordo com Carneiro, Toledo e Almeida (2004), conhecer a geologia propicia a compreensão básica do funcionamento do planeta e estimula as bases do efetivo exercício da cidadania, proporcionando alcançar os objetivos como a formação de cidadãos conscientes, capazes de analisar, julgar e avaliar as atividades humanas em relação ao uso do ambiente. Segundo Dodick e Orion (2003), na maioria das vezes a geologia é mal representada nos currículos escolares da grande maioria dos países, principalmente quando comparada às demais áreas do conhecimento. Negligenciando esta disciplina, os educadores descuidadamente privam estudantes de um pensamento científico que aborda muitos problemas urgentes do mundo, tais como as questões ambientais.

\section{5 - Visita à área de risco}

Uma forma de sensibilizar os novos agentes mirins sobre os desastres naturais relaciona-se às atividades de campo. De acordo com Pessoa e Braga (2012), esta prática pode ser aplicada de forma simples, realizada nas ruas do próprio bairro da unidade escolar, sendo possível identificarem pontos cruciais que potencializam os desastres. Com este mesmo intuito, realizouse uma atividade prática com os agentes. A aula foi complementar ao encontro anterior, sendo mediada por geógrafos da prefeitura e realizada no bairro da escola. A temática da aula foi atrelada às noções básicas de geologia.

Durante o encontro foram realizadas atividades práticas no ambiente escolar, assim como nas ruas do bairro (Figura 5). As práticas abordadas na escola contavam com dinâmicas, que detalhavam sobre a problemática das construções em áreas de risco, e da importância da delimitação de Áreas de Preservação Permanente (APP). Após a conclusão das atividades em sala, foi realizada uma saída a campo na comunidade, analisando a geologia do local, assim como os diferentes tipos de construções. A situação contexto da aula estava pautada no fator risco de desastres em áreas inapropriadas para a construção, ressaltando especificamente os desastres associados aos movimentos de massa, recorrentes no bairro.

Houve a aplicação dos conteúdos conceituais com ênfase aos deslizamentos e às quedas de barreira. Os geógrafos descreveram como estes eventos ocorrem, usando como base as diferentes configurações de morros e formações geológicas do bairro Nova Esperança. Os técnicos comentaram sobre a água como agente deflagrador e a função do sistema de calhas nas residências. Entre os conteúdos procedimentais, o destaque foi para o fator da expressão de ideias a partir de desenhos, da promoção de debates sobre as diferentes percepções de área de risco, bem como da possibilidade de formular hipóteses sobre a questão problema. A evidência dos conteúdos atitudinais estava relacionada ao respeito à opinião do próximo, ao empenho nas atividades de grupo, assim como ao favorecimento da roda de debate entre os estudantes, respeitando o momento de cada um. 
Figura 5 - Geógrafo demostrando as localidades de risco presentes no bairro Nova Esperança

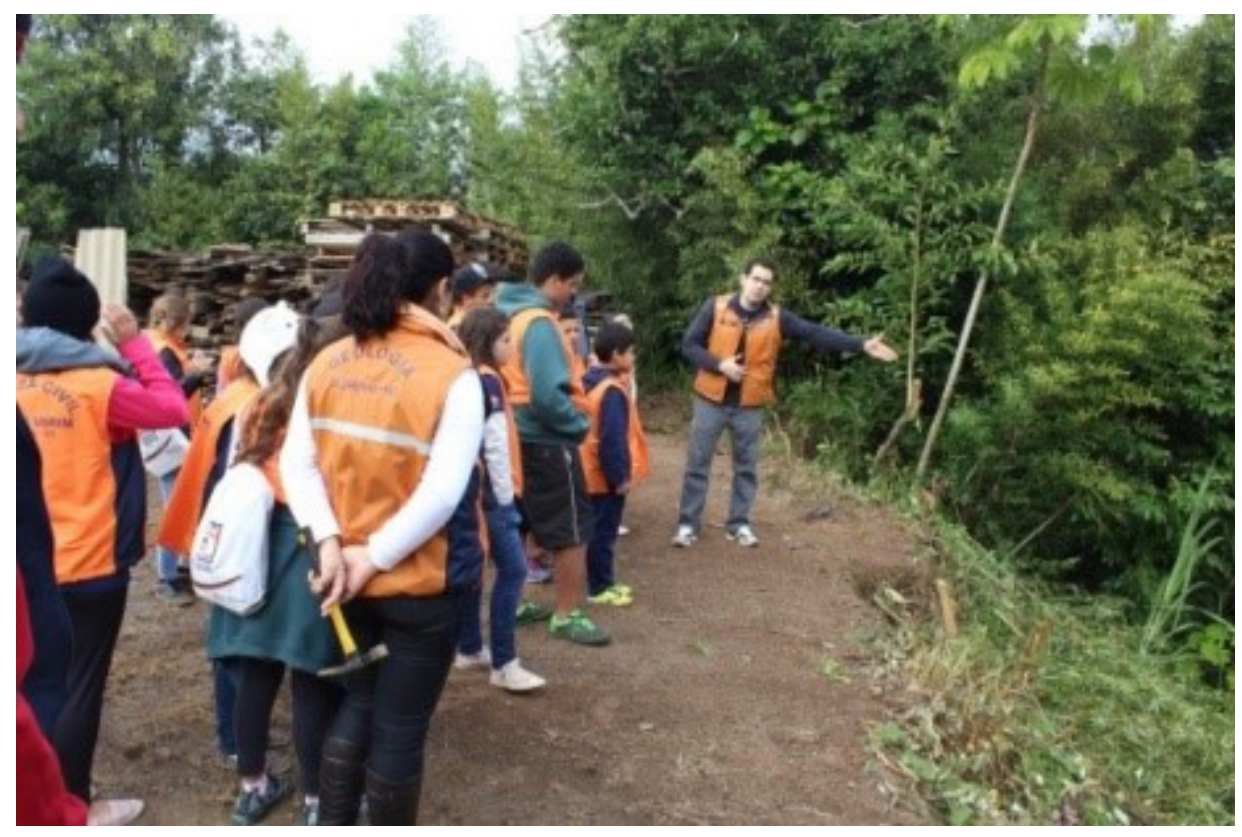

Fonte: Autoria própria.

\section{6 - Saída de campo - Nova Rússia}

Para complementar os conteúdos trabalhados no último encontro e enfatizar o impacto de um desastre natural, os estudantes tiveram a oportunidade de ir a campo para verificar a ocorrência de um evento de grandes proporções, que resultou em perdas econômicas e ambientais para o município durante o ano de 2015. A situação contexto da aula estava pautada a enfatizar o perigo de ocupar áreas inapropriadas.

Com a ajuda de um geógrafo, houve a possibilidade de observar as consequências econômicas e ambientais causadas pelo desastre. Neste encontro foram abordados conteúdos conceituais, como os impactos dos deslizamentos, o fator desencadeante dos desastres naturais, o impacto das intervenções humanas nas encostas e o monitoramento contra riscos. Apesar de pouco evidenciados, os conteúdos procedimentais estiveram presentes durante o encontro, sendo realizadas as rodadas de debates pelos estudantes, sobre as dúvidas que possuíam. Por meio dos debates, evidenciou-se também a presença de conteúdos atitudinais, como procurar conhecer e aceitar a opinião de outras pessoas, valorizando as diferentes ideias.

\section{7 - Aula sobre radioamadores}

Segundo Martins e Spink (2015), as ações de prevenção relacionadas à comunicação de riscos, com objetivo da adequada difusão de informações sobre eventos potencialmente perigosos, têm sido fundamentais como práticas preventivas para a segurança da população. As estações de radioamador constantemente estão envolvidas em comunicações de emergência, neste caso para mitigação, auxiliando em fenômenos causados ou não pelo ser humano (ITU, 2011). Seguindo estes princípios de prevenção e mitigação, a atividade sobre rádio e comunicação de emergência foi o ponto norteador do sétimo encontro. Com a parceria da UBRO radioamadores 
de Blumenau, possibilitou-se enfatizar aos estudantes o método de comunicação emergencial adotado pelo município pós-desastre natural. A situação contexto da aula buscou enfatizar como as pessoas podem se comunicar, caso as comunicações tradicionais sejam perdidas. A presença de atividade prática possibilitou aos estudantes descobrir como utilizar um rádio transmissor.

Houve considerável gama de conteúdos conceituais, abordando-se explicações sobre os processos que devem ser realizados para se tornar um radioamador, sobre os diferentes tipos de comunicações existentes, modelos de rádios utilizados em situações de emergência e como operar um rádio transmissor e um rádio receptor. A presença dos conteúdos procedimentais esteve evidenciada nos debates acerca do tema e na oportunidade do manuseio correto dos equipamentos. $O$ conteúdo atitudinal presente no encontro foi a possibilidade de promover roda de debate entre os estudantes, respeitando o momento de fala de cada um.

\section{8 - Práticas sobre radioamador}

No segundo encontro, o grupo da UBRO proporcionou aos estudantes atividades práticas, como o processo completo de montagem dos equipamentos de rádios. As práticas foram relacionadas ao uso de rádios transmissores e receptores. Os alunos aprenderam a desenvolver uma antena com materiais comuns e montar uma estação de transmissão portátil. A situação contexto da aula foi a utilização de rádios como ferramenta de comunicação em eventos de desastres naturais.

Os conteúdos conceituais estiveram presentes na aula. Os palestrantes da UBRO enfatizaram como montar uma estação de rádio e descreveram os materiais necessários. Exemplificaram por meio de conceitos o processo de montagem de uma antena básica, com poucos recursos. Nos conteúdos procedimentais estiveram presentes o correto manuseio de equipamentos rádio transmissores e a possibilidade de promover métodos alternativos para construção de antenas. Os atitudinais foram expressos durante as atividades em que os alunos respeitaram a opinião do próximo e empenharam-se nas atividades de grupo.

\section{9 - Visita à Odebrecht}

Para elucidar os processos de tratamento de esgoto aos estudantes, realizou-se uma saída a campo para a Odebrecht Ambiental, empresa privada responsável pela coleta e tratamento de esgoto no município (Figura 6). Por meio da exemplificação, os responsáveis técnicos enfatizaram as etapas do tratamento de esgoto, assim como o processo da coleta e do tratamento da água. A situação contexto da aula justificava os motivos pelos quais se deve realizar o tratamento do esgoto e da água, elencando os seus benefícios para a população. Nesta aula, os alunos conheceram também o Museu da Água de Blumenau.

Durante o encontro, foram evidenciados os conteúdos conceituais com a descrição dos processos de tratamento do esgoto bruto e os conceitos sobre a importância da reciclagem e do consumo racional de água. No Museu da Água, os estudantes obtiveram explicações da Estação de Tratamento de Água (ETA), que faz a purificação da água coletada do principal rio do município, detalhando os processos de tratamento, assim como a distribuição. Entre os 
conteúdos procedimentais estiveram presentes a questão de proporcionar o debate por meio de um quiz. Os conteúdos atitudinais evidenciaram a roda de debate entre os estudantes, o respeito da opinião do próximo e a participação nas atividades de grupo.

Figura 6 - Agentes mirins visitando a empresa Odebrecht Ambiental

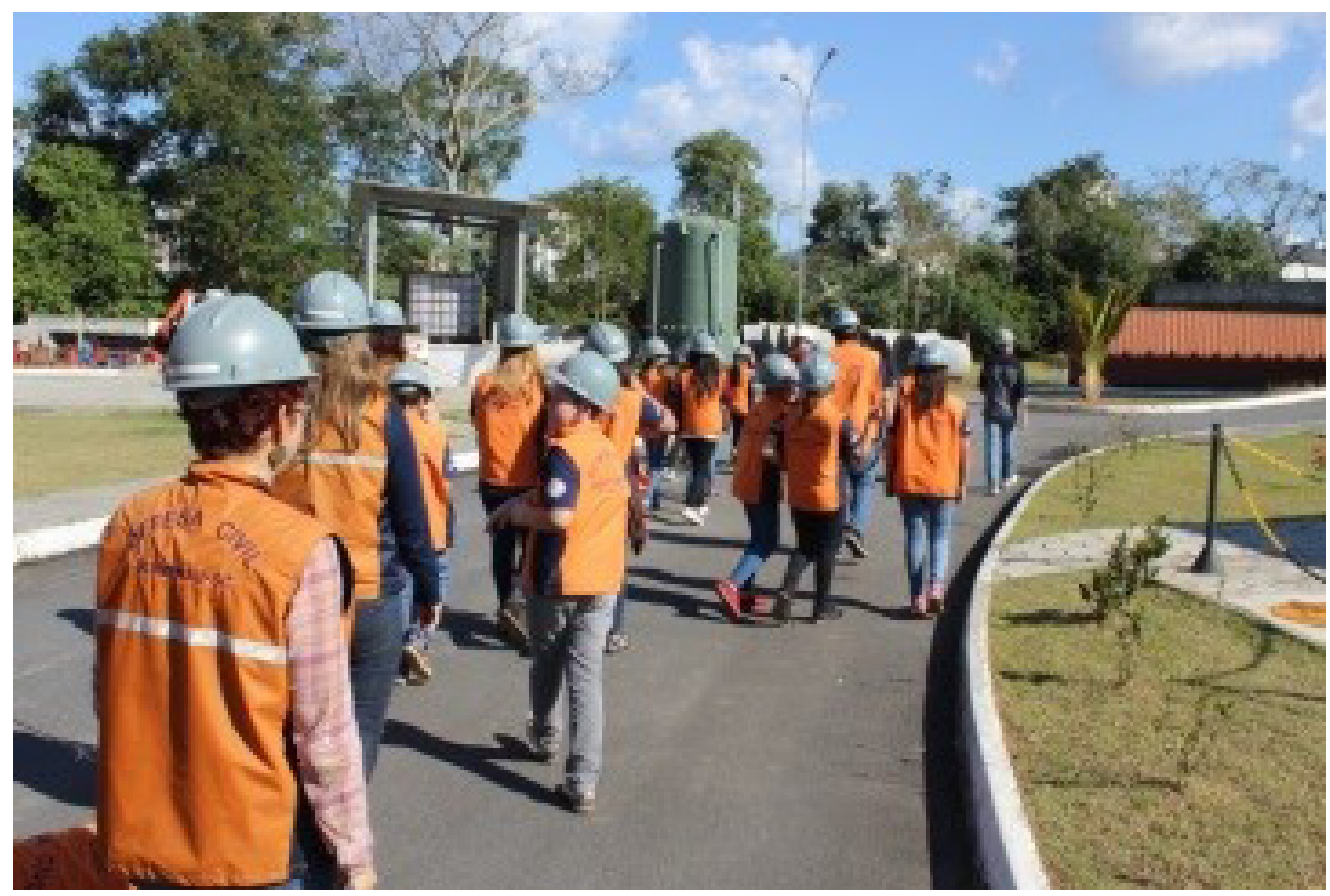

Fonte: Autoria própria.

\section{0 - $23^{\circ}$ Batalhão de Infantaria}

o exército brasileiro é sem dúvida indispensável, seja na segurança do país ou auxiliando durante catástrofes. De acordo com Rosa, Bandeira e Leiras (2014), a participação militar durante os desastres naturais não é algo novo e desempenha um valoroso papel nos esforços para amenizar o sofrimento da população. Procurando reforçar estas competências, os agentes mirins visitaram o $23^{\circ}$ Batalhão de Infantaria. O contexto da aula estava relacionado à definição do Exército e das atividades realizadas pelos oficiais no Município de Blumenau.

Nos conteúdos conceituais houve uma abordagem histórica, possibilitada pela visita ao Museu do Batalhão, assim como uma breve contextualização das atividades práticas desenvolvidas pelos soldados. Por meio dos conteúdos procedimentais, os estudantes tiveram a oportunidade de andar sobre pontes construídas com duas e três cordas, bem como aprender a realizar um circuito de desafios com barreiras e obstáculos. Os conteúdos atitudinais deste encontro estavam exclusivamente relacionados a estimular a participação dos estudantes nas atividades de grupo.

\section{1 - Visitas ao Parque São Francisco de Assis}

A visita ao Parque São Francisco foi uma oportunidade que os estudantes tiveram de conhecer um pouco mais sobre a educação ambiental e a importância da Floresta Atlântica para o município. De acordo com Rosa et al. (2015, p.212):

[...] a educação ambiental é compreendida como uma estratégia de reflexão para a sociedade 
ou grupo pelo qual é desenvolvida no intuito de novamente estabelecer valores e criar uma nova identidade ao indivíduo, considerando que este só poderá ser formado de modo a demonstrar o amadurecimento ambiental com base em um projeto que o insira como formador de opinião e não apenas como cumpridor de ordens ou regras.

O encontro demonstrou aos estudantes a importância de conservar os remanescentes florestais, por meio de um passeio nas trilhas do parque. A situação contexto da aula correlacionava-se com a importância da preservação ambiental no município. Para realizar todas as explicações pertinentes à temática, ocorreu a participação do educador ambiental da Fundação do Meio Ambiente de Blumenau (FAEMA).

Entre os conteúdos conceituais, estiveram presentes o detalhamento da Mata Atlântica e suas características heterogêneas, os diferentes extratos arbóreos, a descrição de algumas espécies de plantas e animais e se exemplificaram os processos hidrológicos presentes no parque. Durante o encontro não houve conteúdos procedimentais, contudo há destaque para os atitudinais. Os alunos respeitaram o ambiente no qual estavam presentes, conforme solicitação do próprio educador ambiental.

\section{2 - Aulas sobre cidadania}

Com a presença da comunicadora Cíntia Lopes na unidade escolar sede dos agentes mirins, o tema do encontro foi uma aula motivacional sobre superação dos medos de falar em público. Segundo Bergmann (2009), o ato de falar em público obteve, na grande maioria das culturas, características particulares. No Brasil, falar em público constitui-se basicamente um desafio, por realçar o indivíduo do grupo.

A situação contexto da aula relacionava-se com a interação do agente mirim na comunidade escolar, estabelecendo métodos para melhorar sua comunicação. Estiveram presentes os conteúdos conceituais como noções básicas de oratória, técnicas de postura, de comunicação visual e exercícios para melhorar a voz. Os conteúdos procedimentais estiveram expressos pela possibilidade de proporcionar o debate de frases elaboradas pelos estudantes e interpretar ideias a partir de leituras. Os conteúdos atitudinais destacados no encontro estiveram focados na valorização das capacidades e das competências de cada estudante, além de fatores como aceitar a opinião de outras pessoas.

\section{3 - Aula sobre primeiros socorros}

De acordo com Leite et al. (2013), acidentes no âmbito escolar constituem preocupações recorrentes, podendo acontecer a qualquer instante, sendo fundamental que os responsáveis que cuidam das crianças detenham conhecimentos para agir frente a esses eventos. Segundo Fioruc et al. (2008), o desprovimento deste conhecimento por parte da própria população propicia uma grande problemática, como o estado de choque ao ver o acidentado, a manipulação inadequada ou indevida da vítima, assim como a solicitação abusiva e, às vezes, dispensável do socorro especializado. Nesta situação a temática abordada aos agentes mirins foram os princípios básicos de primeiros socorros. Entre as atividades práticas, proporcionouse aos estudantes a possibilidade de realizar processos de primeiros socorros, utilizando como 
contexto a possibilidade do enfrentamento destes eventos em sua própria realidade, evitando possíveis acidentes na escola e em sua comunidade.

O mediador do encontro foi um socorrista do Corpo de Bombeiros de Blumenau, que apresentou aos estudantes conteúdos conceituais sobre a ética nos primeiros socorros, a definição de trauma, a explicação da diferença entre urgência e emergência e entre sinal e sintoma. Exemplificou como realizar as fases da avaliação da situação em que se encontra a vítima a ser socorrida, conceituando as técnicas de massagem cardíaca e de reanimação cardiovascular. Por fim, detalhou e explicou o que é uma convulsão, um engasgamento e os diferentes tipos de hemorragias, ferimentos, fraturas e queimaduras. Dentre os conteúdos procedimentais, o socorrista proporcionou aos alunos a possibilidade de realizar a técnica de primeiros socorros para engasgamento em bebês de colo e apresentou o procedimento para estancar hemorragias e realizar a imobilização da vítima em caso de fratura. Neste encontro estiveram presentes o respeito à opinião do próximo, o empenho em atividades de grupo, assim como a possibilidade de proporcionar conhecer e aceitar a opinião de outras pessoas como conteúdos atitudinais.

\section{4 - Simulação do escritório da Defesa Civil na Escola}

Neste encontro foi trabalhado o tema escritório de defesa civil. A situação contexto da aula esteve relacionada em como o agente mirim deveria proceder para repassar as informações sobre o risco de desastre para sua comunidade. Entre os conteúdos conceituais houve o detalhamento das atividades realizadas no órgão da Defesa Civil, exemplificando como o mesmo encontra-se dividido e enfatizando os setores da recepção, da consulta sobre construção, das ocorrências, das orientações e dos abrigos de defesa civil.

Durante o encontro, possibilitou-se a aplicação de conteúdos procedimentais. Para facilitar o processo, os estudantes foram divididos em grupos, os quais foram incumbidos das mesmas responsabilidades realizadas pelo órgão, ou seja, determinado grupo de estudante ficou responsável pelo setor de ocorrências, outro grupo assumiu o papel da população que realizava visitas ao escritório simulado para a obtenção de informações. Por meio desta separação de atividades, foi possível simular uma avaliação em uma réplica de casa que estava sendo construída na própria escola com materiais recicláveis. Os alunos tiveram a tarefa de observar as possíveis rachaduras e outros problemas que potencializam o risco e assim preencher a ficha de avaliação, a qual foi norteadora para o debate realizado posteriormente em sala de aula com as agentes da Defesa Civil. Entre os assuntos debatidos, evidenciou-se a percepção dos estudantes sobre a avaliação realizada em campo. Entre os conteúdos atitudinais, foi possível aprender a divulgar informações à família e outros grupos sociais sobre medidas de prevenção e RRD.

\section{5 - Visita à Câmara de Vereadores Mirins}

Conhecer a Câmara de Vereadores do município de Blumenau foi uma oportunidade exclusiva, pois muitos dos estudantes ainda não tinham tido o contato com este órgão e desconheciam as suas atribuições e as suas competências. Como situação contexto, os alunos descobriram a 
importância que o poder legislativo exerce no município de Blumenau. Neste encontro não foram aplicadas atividades práticas, todavia foi possível participar de uma sessão do projeto da Câmara denominado como "Vereadores Mirins", assim como conhecer as dependências e as estruturas do prédio.

Durante a visitação, a mediadora responsável abordou conteúdos conceituais, entre os quais estavam a contextualização do projeto vereador mirim, que busca realizar a interação de estudantes das escolas do município ao meio legislativo, bem como a realização da visitação atrelada à explicação dos setores da Câmara. Não houve conteúdos procedimentais e, dos atitudinais, evidenciou-se o respeito dos alunos ao conhecimento repassado pelo mediador. Desta forma, ao término do encontro os estudantes realizaram agradecimentos aos membros da Câmara.

\section{6 - Preparação para formatura}

A última interação do projeto antes da formatura foi a realização de um ensaio nas dependências da própria unidade escolar. A situação contexto da aula foi a preparação que o agente mirim deveria possuir para o evento de encerramento a ser realizado na prefeitura. Não houve atividades práticas, e sim a aplicação de um simulado com alguns estudantes em virtude do tempo do encontro. Todos os conteúdos estiveram presentes, entre os conceituais enfatizaram-se informações sobre a formatura, elucidando quais as vestimentas adequadas e como estaria preparado o local para o evento.

Entre os procedimentais foram retratados os métodos de comportamento e a postura a ser adotada pelos estudantes durante a formatura e como realizar um pequeno discurso, tarefa incumbida somente a alguns estudantes. Nos atitudinais, reforçou-se a questão do respeito ao momento de cada participante, especialmente aos membros que iriam compor a mesa de honra e do empenho dos alunos na atividade de grupo. Neste encontro foi perceptível a expectativa que os agentes mirins tinham para o evento, muitos comentaram sobre a possível participação dos membros das suas famílias no dia da formatura.

Encontros adicionais

Nos encontros adicionais os estudantes participaram dos simulados na escola sobre o tema incêndio, do desfile no dia dois de setembro referente ao aniversário do município, da realização de palestras para outros alunos e da participação em atividades do projeto caixa de água, objeto de ensino e aprendizagem que simula um mapa hipsométrico virtual sobre areia, que se encontra no Laboratório Interdisciplinar de Formação de Educadores (LIFE), da Universidade Regional de Blumenau.

$\mathrm{Na}$ formatura os estudantes participam da cerimônia de encerramento do projeto AMDC e receberam o certificado de Agente Mirim de Defesa Civil diretamente das mãos do prefeito. Nesta cerimônia o gestor de Blumenau confirmou a importância do projeto para o município e destacou a relevância das ações desenvolvidas pela DC em parceria com a FURB, as quais começaram a ganhar destaque em nível internacional, com a publicação de um artigo no Boletim PROCIV, da Autoridade Nacional de Proteção Civil de Portugal. 


\section{CONSIDERAÇÕES FINAIS}

O projeto AMDC, em sua terceira turma no ano de 2016, com 30 alunos selecionados, constituiu-se em uma ação de EA para prevenção e RRD de significativa importância para os estudantes. Atualmente, a EA constitui-se em um tema inter, multi e transdisciplinar no contexto escolar, de acordo com os instrumentos legais vigentes, não se constituindo como uma disciplina específica. Contudo, sua transdisciplinaridade não é aplicada da maneira correta, pois nem todos os professores abordam a EA no contexto das suas aulas. Isto acaba fragilizando as condições para que os educandos obtenham um aprofundamento maior sobre o tema ambiental (PETRIS; SEHNEN, 2013). Todavia o projeto AMDC possibilita aos estudantes uma melhor compreensão do ambiente que os envolve, propiciando tomar a decisão mais adequada em uma eventual situação de risco de desastre. De acordo com Rosa et al. (2015), a EA pode ser compreendida como contribuição para promover a participação das populações em processos decisórios, especialmente voltados para a prevenção e redução de riscos de desastres.

As ações do projeto AMDC abrangem pontos positivos, entre os quais é possível mencionar que os alunos apresentam elevado interesse pelas aulas. As atividades realizadas durante os encontros são extremamente dinâmicas e diversificadas. Os mediadores, Bombeiros, Exército, Radioamadores, Geógrafos, entre outros, possuem características exclusivas. Dificilmente os alunos conseguiriam incorporar tantas informações sobre prevenção e RRD somente pela grade curricular em que estão matriculados.

Outro ponto importante está na aplicação das dimensões conceitual, procedimental e atitudinal. Apesar de alguns mediadores não possuírem conhecimentos pedagógicos embasados nestes conteúdos, como no caso das próprias assistentes sociais, as três dimensões estiveram presentes em praticamente todas as aulas. É importante salientar que, durante o processo de ensino e aprendizagem, o docente é um dos principais responsáveis em comandar as etapas necessárias para uma boa mediação didática (MENEZES; CHIAPETTI, 2015). Por isso, ter um planejamento inicial que englobe as atividades propostas e os três pilares da educação, é essencial para melhor capacitar os educandos. Desta forma, é importante retratar o aspecto conceitual, ou seja, aprender a conhecer, buscando a compreensão do conteúdo em sua forma intelectual e científica, do aspecto procedimental, associados com o aprender a fazer, proporcionando por meio de estratégias o aprimoramento dos conceitos de forma experimental e do aspecto atitudinal, vinculados ao aprender a viver e a ser, possibilitando ao estudante durante sua vivência adquirir valores e concepções de mundo (ALMEIDA; BOA; AMARAL, 2015).

Um dos diferenciais do projeto aplicado pela DC foram as saídas a campo. Dos 16 encontros realizados durante o ano de 2016, oito contaram com atividades em campo nas diversas localidades do município. Esta alternância é muito importante para os alunos, pois possibilita maior interação dos mesmos com a temática abordada. De acordo com Viveiro e Diniz (2009), a diversificação de recursos didáticos e de atividades possibilita estimular os estudantes, promovendo atender necessidades e interesses especiais dos próprios alunos. Segundo Campos (2012), é importante salientar que ambientes não formais servem como possibilidade 
para o ensino de ciências, pois permitem explorar uma gama de diversidade de conteúdos, razão pela qual estimula os estudantes pelo contato direto com a natureza, auxiliando na compreensão direta dos fenômenos. Este estímulo se torna primordial para que o aluno obtenha uma aprendizagem significativa (VIVEIRO; DINIZ, 2009).

Contudo, além da importância dos conteúdos e das diferentes estratégias de ensino e aprendizagem e metodologias aplicadas durante os encontros, é fundamental as parcerias realizadas pela prefeitura com outras instituições localizadas no município (Exército, Radioamadores, Bombeiros, entre outros), para que projeto AMDC seja desenvolvido. A possibilidade da construção destas parcerias, especialmente a articulação da Universidade, do poder público, de técnicos capacitados e comunidade escolar, potencializa a qualidade do processo de gestão de riscos de desastres. No caso de Blumenau, o poder público vem levando às comunidades a possibilidade de compreender e se preparar aos possíveis impactos causados por esses eventos adversos. Neste mesmo contexto, a universidade contribui para a melhoria do serviço prestado pela DC ao realizar a análise do projeto AMDC, a partir da efetivada interação entre ações de pesquisa e extensão. De acordo com Nunes e Silva (2011), a extensão universitária viabiliza a relação entre universidade e sociedade por meio do processo educativo, cultural e científico.

A iniciativa empregada pela DC de Blumenau tem se tornado uma importante ferramenta para sensibilizar e capacitar a população frente aos riscos de desastres. Sua importância não deve ficar limitada somente a este município. Essas ações devem ser contínuas e envolver os demais municípios da bacia hidrográfica do rio Itajaí. As cidades vizinhas devem seguir o modelo desenvolvido por Blumenau e adaptar às suas particularidades, buscando assim atingir o status de cidades resilientes aos desastres naturais.

\section{REFERÊNCIAS}

ALMEIDA, O. da S.; BOAS, I. F. V.; AMARAL, C. L. F. Abordagem das dimensões conceitual, procedimental e atitudinal da temática meio ambiente em livros didáticos de ciências com base nos Parâmetros Curriculares Nacionais. Revista Eletrônica de Biologia (REB), v. 8, n. 1, p. 29-53, 2015.

BERGMANN, L. M. A voz dos alunos na sala de aula: a prática da oratória. Educação Unisinos, v. 13, n. 1, p. 76-83, 2009. DOI: 10.4013/edu.2009.131.07

BESSA JÚNIOR, O.; DOUSTDAR, N. M.; CORTESI, L. A. Vulnerabilidade de municípios do Paraná aos riscos de desastres naturais. Caderno Ipardes, v. 1, n. 1, p. 82 -100, 2011.

BRASIL. Lei n 9 9.394, 20 de dezembro de 1996. Estabelece as diretrizes e bases da educação nacional. Diário Oficial da União. Brasília (DF), n²48, dez. 1996.

Secretaria de Educação Fundamental. Parâmetros curriculares nacionais: geografia / Secretaria de Educação Fundamental. Brasília: MEC/ SEF, 156 p. 1998.

. Lei no 12.608, 10 de abril de 2012. Institui a Política Nacional de Proteção e Defesa Civil - PNPDEC.

Diário Oficial da União, Brasília, DF, 2012. 
BRITO JUNIOR, I. de et al. Proposta de um programa de treinamento de desastres naturais considerando o perfil das vítimas. Ambient. soc., São Paulo, v. 17, n. 4, p. 153-176, 2014. DOI: 10.1590/18094422ASOC1092V1742014.

CAMPOS, C. R. P. A saída a campo como estratégia de ensino de ciências: reflexões iniciais. Revista Eletrônica Sala de Aula em Foco, v.1, n.2, p. 25-30, 2012.

CARNEIRO, C. D. R.; TOLEDO, M. C. M.; ALMEIDA, F. F. M. Dez motivos para a inclusão de temas de geologia na educação básica. Revista Brasileira de Geociências, São Paulo, v. 34, n. 4, p. 553-560, 2004.

CRED/UNISDR. The human coast of weather related disaster: 1995 - 2015. Disponível em: <http:// reliefweb.int/sites/reliefweb.int/files/resources/COP21_WeatherDisastersReport_ 2015_FINAL.pdf>. Acesso em: 09 jan. 2017.

DEFESA CIVIL/BLUMENAU. Programa defesa civil na escola - Projeto agentes mirim de defesa civil. Blumenau, p. 16, 2014.

DODICK, J.; ORION, N. Geology as an Historical Science: Its Perception within Science and the Educational System, Science and Education, v. 12, p. 197-211, 2003. DOI: 10.1023/A:1023096001250

FIORUC, B. E.; et al. M. Educação em saúde: abordando primeiros socorros em escolas públicas no interior de São Paulo. Rev. Eletr. Enf., v. 10, n. 3, p. 695- 702, 2008.

ITU. International Telecommunication Union. Role of the amateur and amateur-satellite services in support of disaster mitigation and relief. M.2085-1(2011).

LEITE A. C. Q. B.; et al. Primeiros socorros nas escolas. Revista Extendere, v. 2 n. 1, p. 61-70, 2013.

MARTINS, M. H. da M.; SPINK, M. J. P. Use of disaster risk communication technologies as a preventive healthcare practice. Interface (Botucatu) [online], v. 19, n. 54, p. 503-514, 2015. DOI: 10.1590/180757622014.0593

MENEZES, W. A.; CHIAPETTI, R. J. N. O ensino de geografia na contemporaneidade: O uso da literatura de cordel. Revista Brasileira De Educação Em Geografia, v. 5, n. 10, p. 235 - 257, 2015.

NARVÁEZ, L., LAVELL, A., ORTEGA, G.P. La gestión del riesgo de desastres: Um enfoque basado em procesos. Secretaría General de la Comunidad Andina, Lima, 2009

NUNES, A. L. de P. F.; SILVA, M. B. da C. A extensão universitária no ensino superior e a sociedade. MalEstar e Sociedade, Barbacena, v. 4, n. 7, p. 119-133, 2011.

PESSOA, G. P.; BRAGA, R. B. O trabalho de campo como estratégia de educação ambiental nas escolas: uma proposta para o ensino médio. Pesquisa em Educação Ambiental, v. 7, n. 1, p. 101-119, 2012.

PETRIS, M.R.; SEHNEN, I. A importância da educação ambiental. Maiêutica, v. 1, n. 1, p. 37-43, 2011.

RIBEIRO, F. G. et al. O impacto econômico dos desastres naturais: O caso das chuvas de 2008 em Santa Catarina. Planejamento e Políticas Públicas, n. 43, p. 299 - 322, 2014.

RIBEIRO, J. et al. Relato de experiência sobre o desenvolvimento de ferramentas audiovisuais avaliativas para o Programa "Defesa Civil na Escola", buscando a prevenção de riscos de desastres naturais na cidade de Blumenau-SC. 2016. In: INTERNATIONAL CONFERENCE ON URBAN RISKS, 1, 2016, Lisboa.

Anais... Lisboa: CERU - European Centre on Urban Risks, 2016. p. 843 - 850.

ROSA T. da S.; et al. A educação ambiental como estratégia para a redução de riscos socioambientais. Ambient. soc., São Paulo, v. 18, n. 3, p. 211-230, 2015. DOI: 10.1590/18094422ASOC1099V1832015. 
ROSA, P. R. S. da.; BANDEIRA, R. A. de M.; LEIRAS, A. O papel das forças armadas brasileiras em gestão de operações em desastres naturais com ênfase em logística humanitária. 2014. In: CONGRESSO DE PESQUISA E ENSINO EM TRANSPORTE, 28, 2014, Curitiba. Anais... Curitiba - PR. 2014.

UNISDR. Como construir cidades mais resilientes - um guia para gestores públicos locais: Uma contribuição à Campanha Global 2010-2015 - Construindo Cidades Resilientes - Minha Cidade está se preparando! Genebra, Novembre de 2012.

VIVEIRO, A. A.; DINIZ, R. E. da S. Atividades de campo no ensino das ciências e na educação ambiental: refletindo sobre as potencialidades desta estratégia na prática escolar. Ciência em Tela, v. 2, n. 1, p. 1-12, 2009.

XAVIER, D. R.; BARCELLOS, C.; FREITAS, C. M. de. Eventos climáticos extremos e consequências sobre a saúde: o desastre de 2008 em Santa Catarina segundo diferentes fontes de informação. Ambient. soc., São Paulo, v. 17, n. 4, p. 273-294, dez. 2014 . DOI: 10.1590/1809-4422ASOC1119V1742014.

YIN, R. K. Estudo de caso: planejamento e métodos. Porto Alegre: Bookman, 2005.

ZABALA, A. A prática educativa: como ensinar. Porto Alegre: Artmed, 1998.

Artigo recebido em: 08/05/2017

Aprovado em: 18/12/2017

\section{Contato para correspondência:}

Rafaela Vieira.E-mail: arquitetura.rafaela@gmail.com 